\title{
Lead in superconductivity patent race to go to Japan?
}

\section{Nobel prizewinners running second $\square$ Patents filed on three continents}

Tokyo

THE Japanese patent office revealed on 20 July that Tokyo University has beaten International Business Machines (IBM) Co. off the mark in filing for a patent that describes the composition and structure of lanthanum-barium-copper oxide, the high-

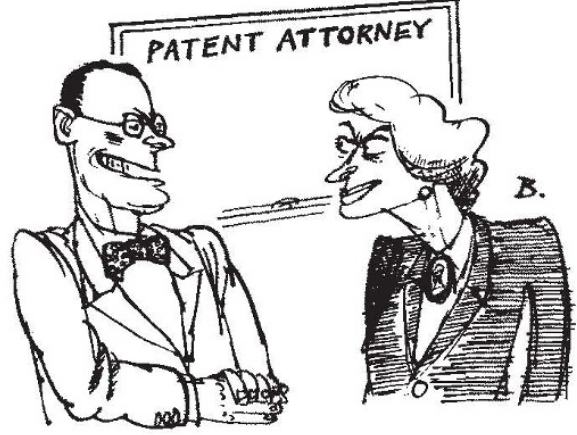

At near-normal temperatures, these new superconductors can keep a supply of money going indefinitely...

temperature superconductor discovered by Nobel prizewinners Georg Bednorz and Alex Müller at IBM Zurich in 1986.

The patent application is the first of its kind to be made public and it draws attention to differences between Japanese, European and US patent laws.

A team at Tokyo University led by Professor Shoji Tanaka filed the application for the patent in Japan on 17 January 1987 on the basis of its confirmation of the IBM discovery and, more important, its determination that the structure of lanthanum-barium-copper oxide is the same as that of crystals of $\mathrm{K}_{2} \mathrm{NiF}_{4}$. According to Tanaka, IBM Zurich filed a "very similar" application in Europe six days later.

Michael Starks, an IBM spokesman on patents, confirmed that such a European patent had been filed. And he says that IBM has also applied for high-temperature superconductor patents in the United States and Japan. The Tokyo University patent was made public under Japanese law which requires that all patents are published 18 months after application to allow objections to be raised before the patent is awarded as in Europe.

As both Japan and Europe determine patent priority on the basis of who is 'first to file', the Tokyo University patent has priority, at least in Japan (and also in Europe if a patent application has also been filed there on the basis of the Japanese application).

This contrasts with the situation in the United States where the 'first to invent' has priority. But the US rule applies only to research carried out by researchers based in the United States or temporarily assigned overseas for research on behalf of the United States. And IBM cannot invoke this rule even for a US patent because its research was carried out in Zurich by non-US citizens.

IBM could file an objection in Japan stating that the Tokyo University patent application is 'obvious' because the superconductor was described by Bednorz and Müller in a scientific publication in September 1986. But, if successful, this course of action would bar both Tokyo University and IBM from getting a Japanese patent, according to Yasunori Ohtsuka, a patent attorney in Tokyo. And such action would also run counter to IBM's claims for the European patent.

According to Tanaka, both his patent and IBM's European patent application were made on the grounds that the crystal structure of the superconductor was not described in the September 1986 paper.

Under European patent law, applications for patents cannot be made for discoveries that have already been published. This contrasts with the United States, where patent applications can be filed within one year after publication, and Japan where six months is allowed.

But the real battle over superconductor patents has yet to begin. Professor C. W. Chu filed an application for a US patent for yttrium-barium-copper oxide within days of the Tokyo University application. The yttrium-based copper oxides superconduct at higher temperatures than those made from lanthanum and barium and applications of the yttrium-based material are much more advanced.

Unlike Japanese patents, US patent applications remain confidential until granted. And it is only after they are awarded that they can be contested. Chu's patent is expected to be awarded very soon. And hundreds of Japanese patents for applications of the new superconductors are also expected to be revealed by the Japanese patent office over the next few months. Clearly patent lawyers around the world are going to have their hands full in determining priority when this barrage of patent applications is made public.
François Kourilsky to head CNRS

\section{Paris}

THE French Research Ministry has named François Kourilsky, a 53-year-old biologist, as director of the Centre National de la Recherche Scientifique (CNRS). Kourilsky fills the vacancy left after Serge Feneuille unexpectedly resigned last month (see Nature 334, 5; 1988).

If it is unusual for a biologist to head France's largest public-sector research organization (a long line of physicists have previously had the job), Kourilsky's pedigree makes him a natural choice to accompany Hubert Curien's second tour as Research Minister in the new Mitterrand government. From 1983 to 1987, Kourilsky was vice-president of the Conseil Scientifique de la Recherche et de la Technologie (CSRT), the government-appointed committee of academics and industrialists that advises the ministry on research policy. Curien, as research minister, is its president.

The CSRT was set up under the previous socialist government as a symbol of glasnost and took an active part in policymaking, recommending annual job creation for researchers and a steady budget progression. But, when the socialists lost power in 1986, the CSRT became something of a white elephant and was largely circumvented (see Nature 328, $567 ; 1987$ ). Although the government has a statutory obligation to submit its research budget proposals to the CSRT for comment, the 1988 science budget was shown to the committee only a few hours before it was announced to the press. Kourilsky's appointment is therefore yet another sign of President Mitterrand's wish to pick up where he left off in 1986, despite promises to let the political centre have more say.

Kourilsky is well known in the field of immunology and, last year, set up an AIDS research unit with Jean-Claude Chermann at Marseilles, with funding from the Institut National de la Santé et de la Recherche Médicale (INSERM). After a stormy time under the previous government, CNRS researchers will welcome Kourilsky's appointment. But, according to a Research Ministry communiqué, he has been asked to "adapt and modernize the functioning of this large organization, making it more supple, while taking account of the predominant role of the personnel and their motivations". This task has fallen to successive directors, none of whom has been able to make significant changes.

Peter Coles

\section{Erratum}

In last week's account (pages 287-290) of our investigation of the claims of Dr Jacques Benveniste and his associates, Fig. 3 was cited in place of Figs 4 and 5, and should have been cited at the bottom of the first column on page 289 . 